\title{
ESTIMATION OF INDUSTRIAL MATERIAL FLOW PRODUCED BY „DEVNYA CEMENT“AD FOR REMEDIATION OF ACID SPILS
}

\author{
Svetla Marinova, Elena Zlatareva
}

\begin{abstract}
The issues of acidity and liming of soils were raised in Bulgaria more than 60-70 years ago. „Devnya Cement“ produces the Restart product, as an integral part of the process in the installation of cement clinker in a dry way and contains a high amount of calcium oxide (lime material). The aim of the study is to establish the effect of the studied product RESTART and possibilities for its use as an ameliorant on acid soils. A vegetation experiment was performed with a test crops of corn with different percentages of ameliorant. The chemical and physico-mechanical parameters of the treated soil were studied and the changes in the degree of soil acidity were established. Preliminary consumption rates of the ameliorant have been determined, when it is used for amelioration of acid soils. The chemical characteristics of the plant samples show, that the values of the chemical elements are in optimal concentrations and cannot have a harmful effect, when used as animal feed. To correct the acidity of soils with similar acidic properties as in the Devnya region, it may be recommended to apply about $1-2 t /$ daa of the studied ameliorant.
\end{abstract}

Keywords: ameliorant, characteristics, neutralizing ability

\section{INTRODUCTION AND PURPOSE OF THE RESEARCH}

Bulgaria is a country with insufficient land for agricultural use. Agricultural lands occupy $51 \%$, and arable - about $46 \%$ of the country. Every year the areas of lands with impaired soil fertility increase. Millions of acres of arable land are affected by erosion. Acidic soils occupy over $7 \%$ of arable land, and as a result of the use of physiologically acidic mineral fertilizers, the share of medium to strongly acidic soils is increasing.

According to data from the Soil Map of Bulgaria (M 1: 400,000) about 43000000 daa in the country are occupied by moderately and strongly acid soils ( $\mathrm{pH}$ 6.0), which contain the toxic soil acidity of plants.

Of these, about 22000000 daa are included in agricultural use - as arable land for agriculture, as pastures and meadows for livestock, as orchards and others.

In all moderately and strongly acidic soils in the country, there is the toxic for plants metabolic acidity (exchange AL) and the soil reaction is lower than $\mathrm{pH}$ 6.0. [7]. This acidity, as a manifestation of the highly acidic acid systems of soil colloids, causes acid disharmony in the mineral nutrition of plants. The results are difficult germination, compromising yield and deteriorating quality. In addition, this acidity is an expression of acid degradation of clay colloids in soils (podzolization), which is a major mechanism for the degradation of acid soils. Accordingly, all these soils are subject to neutralization reclamation by importing lime materials (lime) in order to increase the yields and quality of production $[2,5,6,9,10]$.
"Devnya Cement" AD produces the product Restart, which is an integral part of the production process in the installation for the production of cement clinker by dry method and contains a high amount of calcium oxide (lime material).

For the production of cement clinker, mainly natural rock materials are used, which after crushing and grinding form a "raw material mixture" consisting of natural raw materials and industrial products containing the main mineral-forming oxides $-\mathrm{CaO}$, $\mathrm{SiO}_{2}, \mathrm{Al}_{2} \mathrm{O}_{3}$ and $\mathrm{Fe}_{2} \mathrm{O}_{3}$.

Natural raw materials - limestone, marl and sand are mined in open pits. Iron-containing additives (in smaller quantities) are residual products from other branches of industry (in accordance with the concept of "circular economy").

The approximate composition of the raw material mixture at the entrance is $70 \%$ limestone, $20 \%$ marl and $10 \%$ corrective additives - mainly iron-containing materials (fayalite) and sand.

In the production of cement clinker, part of the fine dust-air mixture of the exhaust gases from the cement kiln is removed from the system by means of a fan, providing the necessary draft. The gases are cooled sharply and then pass through a cooling tower, where their temperature is further reduced. The dust is effectively captured by an electrostatic precipitator and transported to a specialized silo [1].

Furnace dust is an integral part of cement production and is a complex combination of finely divided inorganic particles (a substance with variable composition, a product obtained by complex reactions).

This results in a material with a high degree of decarbonization and a high content of calcium oxide, 
alkaline sulphates and alkaline chlorides, called by the trade name Restart.

The aim of the study is to establish the effect of the studied product RESTART and possibilities for its use as an ameliorant on acid soils.

\section{METHODOLOGY AND STAGES OF THE RESEARCH}

To establish the effect of industrial flow as an ameliorant on acid soils, a vegetation experiment was performed.

The aim of the vegetation experiments is to determine the optimal reclamation norms of Restart for removal of harmful soil acidity.

Soil taken from agricultural land on the left side of the road from the village of Nikolaevka to the village of Drandar was used for practical verification of the neutralizing capacity of the delivered industrial material flow. The distance to the town of Devnya is approximately $17 \mathrm{~km}$ north of the town. The soil is dark gray forest soil and slightly eroded. Heavy sandy-clayey with acidic soil reaction $\mathrm{pH}$ 5.3 and toxic to plants metabolic acidity, vol. AL2.6 meq. $/ 100 \mathrm{~g}$ of soil.

The experiment was performed according to the following scheme.

\section{SCHEME OF EXPERIMENT}

"Kneza" corn crop test 509

1. Control - acidic soil $1.3 \mathrm{~kg}$

2. Control - acidic soil $1.3 \mathrm{~kg}+\mathrm{NPK}$

3. Acidic soil $1.3 \mathrm{~kg}+$ Restart with a rate calculated by $1 / 2$ of the exchange aluminum + NPK

4. Acidic soil $1.3 \mathrm{~kg}+$ Restart with a rate calculated 2.0 times on the exchange aluminum + NPK

5. Acidic soil $1.3 \mathrm{~kg}+$ Restart with a rate calculated by $\mathrm{H}_{8.2}+\mathrm{NPK}$.

The chemical and physicochemical parameters of the treated soil were studied and the changes in the degree of soil acidity were assessed. Preliminary Restart consumption rates have been set when using them for amelioration of acid soils.

The following physicochemical values were used to characterize the physicochemical properties of the soil:

* $\mathrm{pH}$ of the soil, which expresses the equilibrium concentration of hydrogen ions in the soil - water suspension, formed by the ion exchange balance between the soil colloids and the soil solution.

* Cation exchange adsorption capacity $-\mathrm{T}_{8.2}$ of the soil, which is a measure of its colloidity and chemical reactivity.
* Cationic exchange capacities of the strong acid ion exchanger

* On the weakly acidic ion exchanger - Ta of the soil, which measure the share of colloidal surfaces, reacting respectively as a strong acid and as a weak acid in the adsorption of hydrogen ions.

* Total hydrolytic acidity (volume $\mathrm{H}_{8,2}$ ), which measures the amount of all cations with acidic functions (hydrogen, aluminum, manganese, etc).

- Exchange acidity (exchange $\mathrm{Al}$ ), which is a measure of the amount of cations with acidic functions adsorbed only on the strong acid ion exchanger of soil colloids.

Degree of saturation with bases, which expresses in percent the part of the adsorption surface of soil colloids. This is the degree of neutralization of the strong acid and weak acid ion exchanger of colloids with strong basic cations (calcium, magnesium, potassium) $[3,4]$.

\section{RESULTS AND DISCUSSION}

Studies on the RESTART material, in the form of a powder passing through a sieve of about $1 \mathrm{~mm}$ and a dry matter of $99.94 \%$, showed that the agrochemical, chemical and physico-mechanical parameters show, that it does not contain harmful substances, that can cause negative impact when used as an ameliorant on acidic soils. It has a great neutralizing ability. Its main property is direct or hydrolysis as a strong base and its ability to participate in neutralization interactions with the acid systems of the soil adsorbent. Restart is a fastacting and effective ameliorant. Agrochemical analyzes show, that the content of the total amounts of nutrients nitrogen, phosphorus and potassium is low. The values of the common forms of heavy metals are lower than those specified in the legislation [1].

The more important physicochemical data for the soil with which the vegetation experiment was performed are presented in the following Table 1.

According to the basic constitution, this is a podzolic soil (A chorus), with $\mathrm{pH}=5.3(\mathrm{pH}<6.0)$. The reaction is slightly acidic on bicarbonate rocks and bases $<$ Tca.

According to Ganev's physicochemical classification, the soil is moderately acidic. According to the colloidal reactivity $\mathrm{T}_{8.2}=30-20$ $\mathrm{meq} / 100 \mathrm{~g}$, the soil is moderately colloidal. According to the predominant clay mineralogy $\mathrm{T}_{\mathrm{CA}}=68.13 \% \mathrm{~T}_{8.2}$ is ilite, evolving to illitekaolinite-bases $60-40 \% \mathrm{~T}_{8.2}$. 
Table 1. Sorption properties of the initial soil

\begin{tabular}{|c|c|c|c|c|c|c|c|c|c|}
\hline \multirow{2}{*}{ Object } & \multirow{2}{*}{$\mathbf{p H}$} & $\begin{array}{c}\text { Degree of } \\
\text { saturation } \\
\text { with bases }\end{array}$ & $\mathbf{T}_{\mathbf{8 , 2}}$ & $\mathbf{T}_{\mathbf{C A}}$ & $\mathbf{T}_{\mathbf{A}}$ & $\begin{array}{c}\text { Exch. } \\
\mathbf{H 8 . 2}\end{array}$ & $\begin{array}{c}\text { Exch. } \\
\mathbf{A l}+\mathbf{H}\end{array}$ & $\begin{array}{c}\text { Exch. } \\
\mathbf{C a}\end{array}$ & $\begin{array}{c}\text { Exch. } \\
\mathbf{M g}\end{array}$ \\
\cline { 2 - 9 } & $\% \mathrm{~T}_{8,2}$ & \multicolumn{7}{|c|}{ meq./100 g of soil } \\
\hline $\begin{array}{c}\text { Soil from } \\
\text { the village of } \\
\text { Drandar }\end{array}$ & 5,3 & 55,90 & 20,4 & 13,9 & 6,5 & 9,9 & 2,6 & 10,0 & 1,4 \\
\hline
\end{tabular}

The results of the conducted agrochemical and chemical analyzes are presented in Tables 2 and 3. They show, that the soil is very poorly stocked with phosphorus, moderately stocked with potassium and well stocked with mineral nitrogen. The humus content is $2.35 \%$, which classifies it as medium humus. The electrical conductivity of the soil solution is low, which indicates that there are very few water-soluble salts and this soil is not saline.

Table 2. Agrochemical characteristics of the soil with which the vegetation experiment was performed

\begin{tabular}{|c|c|c|c|c|c|}
\hline \multirow{2}{*}{ Object } & Humus & $\begin{array}{c}\text { Elektropro } \\
\text { conductivity }\end{array}$ & $\begin{array}{c}\mathbf{\Sigma} \mathbf{N}- \\
\mathbf{N H}_{\mathbf{4}}+\mathbf{N O}_{\mathbf{3}}\end{array}$ & $\mathbf{P}_{\mathbf{2}} \mathbf{O}_{\mathbf{5}}$ & \multicolumn{2}{|c|}{$\mathbf{K}_{\mathbf{2}} \mathbf{O}$} \\
\cline { 2 - 6 } & $\mathbf{\%}$ & $\mathbf{m S / \mathbf { c m } ^ { \mathbf { 3 } }}$ & $\mathbf{m g} / \mathbf{K g}$ & \multicolumn{2}{|c|}{$\mathbf{m g / 1 0 0 g}$} \\
\hline $\begin{array}{c}\text { Soil from the village of } \\
\text { Drandar }\end{array}$ & 2,35 & 0,07 & 35,7 & 2,6 & 11,2 \\
\hline
\end{tabular}

Table 3. Chemical analysis - total content of heavy metals in $\mathrm{mg} / \mathrm{kg}$ in the soil

\begin{tabular}{|c|c|c|c|c|c|c|}
\hline \multirow{2}{*}{$\begin{array}{c}\text { Soil from the village of } \\
\text { Drandar }\end{array}$} & $\mathbf{C u}$ & $\mathbf{Z n}$ & $\mathbf{M n}$ & $\mathbf{F e}$ & $\mathbf{P b}$ & $\mathbf{C d}$ \\
\cline { 2 - 7 } & 18,5 & 55,5 & 625 & 1830 & 15,0 & 1,00 \\
\hline
\end{tabular}

The total content of the studied heavy metals is well below the maximum allowable concentrations for arable land. The soil is defined as practically unpolluted with heavy metals and multifunctional.

Table 4. Required amount of Restart, calculated and imported by variants

\begin{tabular}{|l|c|c|}
\hline \multicolumn{1}{|c|}{ Variants } & g/vessel & \% of soil weight \\
\hline Soil from the village of Drandar, sown with corn & & \\
\hline 1. Soil control & 0,0 & 0,0 \\
\hline 2. Soil + NPK & 0,0 & 0,0 \\
\hline 3. Soil + Restart on 1/2 of exchange, Al + NPK & 0,48 & 0,048 \\
\hline 4. Soil + Restart, 2 times by volume, Al + NPK & 1,97 & 0,198 \\
\hline 5. Soil + Restart according to H8.2 + NPK & 3,66 & 0,366 \\
\hline
\end{tabular}

On all variants as a permanent fertilizer background is added on $250 \mathrm{mg}$ of nitrogen, phosphorus and potassium in the form of ammonium nitrate, monocalcium phosphate and potassium chloride were added to all variants as a permanent fertilizer background. A control version with mineral fertilization is included.
The vegetation experience is based on the above-mentioned soil difference in pots with a capacity of $1.5 \mathrm{~kg}$ in 3 replicates, a total of 15 pots. Restart was introduced in norms calculated according to the scheme of the vegetation experience. 
The well-homogenized mixture of soil, ameliorant and mineral fertilizers is left to compost for some time, and by irrigation with water the PPV (maximum soil moisture capacity) is maintained. The purpose of composting is to give the ameliorant time to react with the soil solution and to be able to displace the exchangeable aluminum and saturate the soil uptake complex with calcium. The sowing of corn variety "Kneja 509" with 7 grains per pot was performed. Corn sprouted en masse in all variants, than thinned into 5 plants per pot. Daily watering of the plants was carried out, according to the maximum field moisture content.

Photographs were taken before retrieving the experiment.

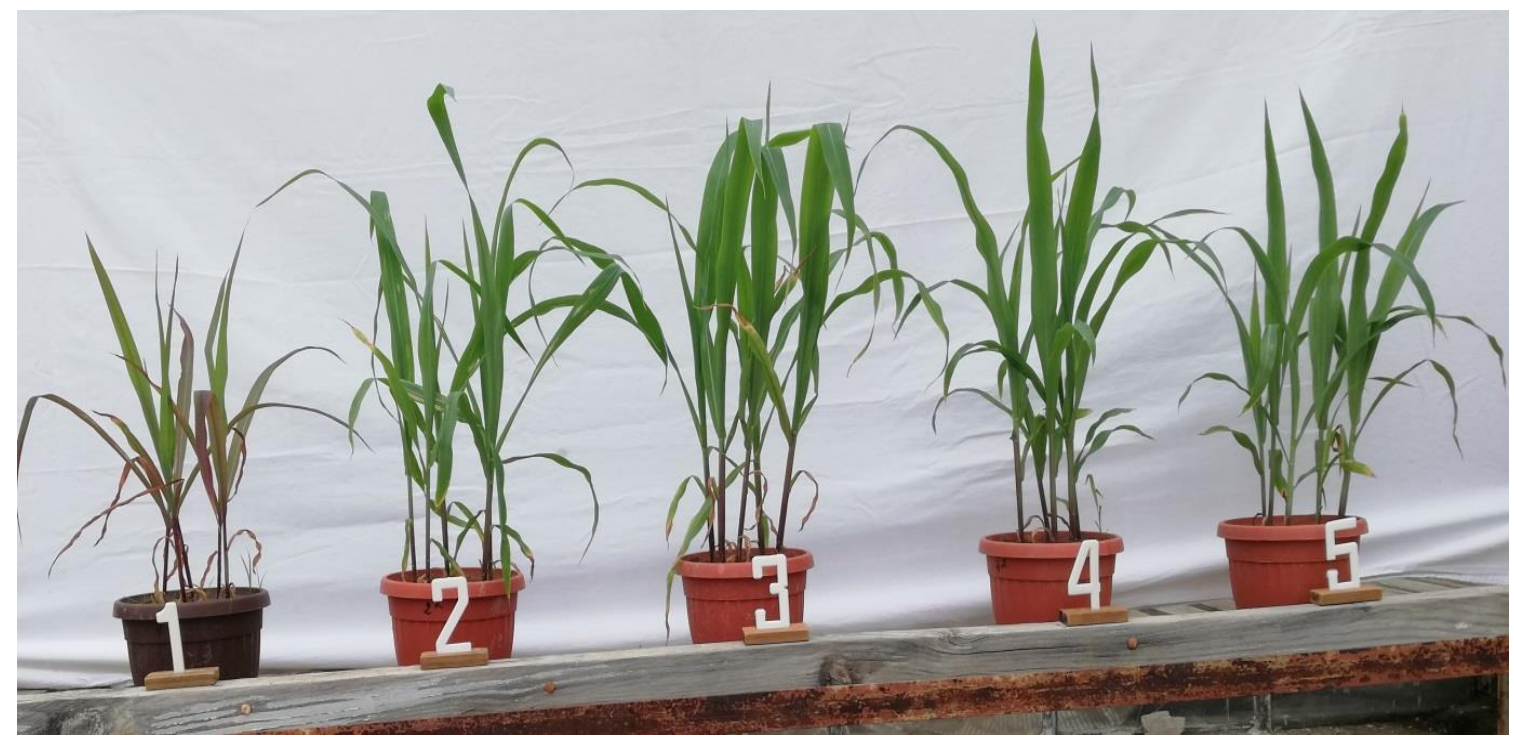

Variants of the study: 1 lime. - control-clean soil,

2 var. - soil with NPK,

3 var. - soil + Restart on $1 / 2$ of exchange. Al + NPK

4 var. - soil + Restart 2 times in exchange. $\mathrm{Al}+\mathrm{NPK}$

5 var.- soil + Restart on H8,2 + NPK

\section{YIELD FROM PLANT PRODUCTS}

After harvesting the experiment, the yield from above-ground biomass of the tested crop of silage corn was reported. The fresh mass of plants is determined by weight in grams per container. Vegetation experience shows, that maize grows normally on the soil with the applied ameliorant.

Table 5. Yield of test maize crop in $\mathrm{g} /$ court

\begin{tabular}{|l|c|c|c|c|}
\hline \multicolumn{1}{|c|}{ Variants } & $\mathbf{1}^{\text {st }}$ repetition & $\mathbf{2}^{\text {nd }}$ repetition & $\mathbf{3}^{\text {rd }}$ repetition & Average \\
\hline 1. Soil control & 10,82 & 10,31 & 9,66 & $\mathbf{1 0 , 2 6}$ \\
\hline 2. Soil + NPK & 30,12 & 31,0 & 28,80 & $\mathbf{2 9 , 9 7}$ \\
\hline $\begin{array}{l}\text { 3. Soil + Restart on 1/2 } \\
\text { of exchange, Al + NPK }\end{array}$ & 35,34 & 29,20 & 30,18 & $\mathbf{3 1 , 5 7}$ \\
\hline $\begin{array}{l}\text { 4. Soil + Restart 2 times } \\
\text { in exchange, Al + NPK }\end{array}$ & 27,20 & 26,66 & 27,24 & $\mathbf{2 7 , 0 3}$ \\
\hline $\begin{array}{l}\text { 5. Soil + Restart on } \\
\text { H8.2 + NPK }\end{array}$ & 19,86 & 22,20 & 20,85 & $\mathbf{2 0 , 9 7}$ \\
\hline
\end{tabular}


From the results shown in Table 5 it can be seen that with the increase of the norm of the ameliorant the yield of the tested culture also increases, in comparison with the control variant. At the highest rate of ameliorant, a decrease in yields is observed. A probable cause of the depression in the development and yield of corn is the disturbed balance in the intake and absorption of nutrients by plants with a significant increase in soil $\mathrm{pH}$ and water-soluble salts, which leads to low salinization of the soil

\section{QUALITY OF PLANT PRODUCTS}

For a more correct interpretation of the results of the studied nutrients in plants, a comparison was made with the optimal content of nutrients in the tested Begman crop. The results are given in Table 6. Optimal Begman nutrient content Table.

Table 6. Optimal nutrient content according to Begman Crop

\begin{tabular}{|c|c|c|c|c|c|c|c|c|}
\hline Crop & Zn & Cu & Mn & P & K & Ca & Mg & N \\
\hline & \multicolumn{6}{|c|}{ mg/kg dry weight } & \multicolumn{7}{|c|}{} \\
\hline $\begin{array}{c}\text { Corn } \\
40-60 \text { cm height }\end{array}$ & $20-60$ & $6-12$ & $30-150$ & $0,3-0,6$ & $3,5-5,0$ & $0,3-1,0$ & $0,15-0,30$ & $2,5-5,0$ \\
\hline
\end{tabular}

Table 7. Chemical composition of plant production from silage corn

\begin{tabular}{|c|c|c|c|c|c|c|c|c|c|}
\hline Variants & $\mathbf{Z n}$ & $\mathbf{C u}$ & Mn & $\mathbf{F e}$ & $\mathbf{P}$ & $\mathbf{K}$ & $\mathbf{C a}$ & Mg & $\mathbf{N}$ \\
\hline & \multicolumn{4}{|c|}{$\mathrm{mg} / \mathrm{kg}$} & \multicolumn{5}{|c|}{$\%$} \\
\hline \multicolumn{10}{|c|}{ Soil from the village of Drandar } \\
\hline 1. Soil control & 20 & 3 & 62 & 130 & 0,15 & 2,6 & 1,1 & 0,9 & 1,3 \\
\hline 2. Soil + NPK & 23 & 5 & 81 & 151 & 0,33 & 4,1 & 1,0 & 0,9 & 1,8 \\
\hline $\begin{array}{l}\text { 3. Soil + Restart on } 1 / 2 \text { of } \\
\text { exchange, } \mathrm{Al}+\mathrm{NPK}\end{array}$ & 16 & 4 & 60 & 147 & 0,34 & 4,5 & 1,5 & 1,2 & 2,3 \\
\hline $\begin{array}{l}\text { 4. Soil + Restart } 2 \text { times } \\
\text { in exchange, } \mathrm{Al}+\mathrm{NPK}\end{array}$ & 16 & 4 & 60 & 146 & 0,34 & 5,0 & 1,8 & 1,5 & 1,8 \\
\hline $\begin{array}{l}\text { 5. Soil + Restart on H8.2 } \\
\text { + NPK }\end{array}$ & 14 & 5 & 58 & 128 & 0,32 & 5,4 & 2,1 & 1,5 & 1,9 \\
\hline
\end{tabular}

From the performed plant analysis of corn by variants it can be seen, that as the rate of Restart increases, the content of total nitrogen in the plant mass increases. The content of $\mathrm{P}$ does not change significantly, but of $\mathrm{K}$ is in the range of 2.6 to $5.4 \%$ and there is a clear pattern with increasing the rate of ameliorant. All tested heavy metals visibly do not change. (Table 7).

\section{CHANGES IN SOIL PROPERTIES AS A RESULT OF RECOMMENDATION}

After harvesting the experiment, average soil samples were taken from all variants. The following were determined: the cationic sorption capacity at
$\mathrm{pH} 8.2\left(\mathrm{~T}_{8.2}\right)$, total exchange adsorbing hydrogen dissociating to $\mathrm{pH} 8.2$ (exchange $\mathrm{H}_{8.2}$ ), exchanged $\mathrm{Al}$ (equivalent to exchange acidity) and the degree of saturation with bases (Table 10).

The results show, that the main property of the used ameliorant is its ability to participate in neutralization interactions with the acid systems of the soil adsorbent [7].

In variant 3 , part of the toxic acidity is neutralized and the $\mathrm{pH}$ increases to 5.4 , the exchangeable aluminum decreases from $2.6 \mathrm{meq} / 100 \mathrm{~g}$ to $1.2 \mathrm{meq} / 100 \mathrm{~g}$. In variant 4 , almost complete neutralization of the metabolic acidity $(0.2 \mathrm{meq} / 100 \mathrm{~g}$ of soil) and $\mathrm{pH}=5.95$ is observed. 
Table 8. Sorption properties of the soil after the end of the vegetation experiment

\begin{tabular}{|c|c|c|c|c|c|c|c|c|c|c|}
\hline Variants & $\begin{array}{c}\mathbf{p H} \\
\mathbf{H}_{\mathbf{2}} \mathbf{O}\end{array}$ & $\mathbf{T}_{\mathbf{8}, \mathbf{2}}$ & $\mathbf{T}_{\mathbf{C A}}$ & $\mathbf{T}_{\mathbf{A}}$ & $\mathbf{H}_{\mathbf{8}, \mathbf{2}}$ & $\begin{array}{c}\text { Exch. } \\
\mathbf{A L}\end{array}$ & $\begin{array}{c}\text { Exch. } \\
\mathbf{C a}\end{array}$ & $\begin{array}{c}\text { Exch. } \\
\mathbf{M g}\end{array}$ & $\begin{array}{c}\text { Degree to } \\
\text { satiety } \\
\text { with bases }\end{array}$ \\
\hline & - & \multicolumn{7}{|c|}{$\mathbf{M e q} / \mathbf{1 0 0 g}$} \\
\hline 1. Soil control & 5,15 & 21,0 & 14,2 & 6,8 & 10,0 & 2,5 & 9,6 & 1,4 & 52,38 \\
\hline 2. Soil + NPK & 5,0 & 20,9 & 14,1 & 6,8 & 9,8 & 2,4 & 9,5 & 1,4 & 53,11 \\
\hline $\begin{array}{c}\text { 3. Soil + Restart on } \\
\text { 1/2 of exchange, } \\
\text { Al + NPK }\end{array}$ & 5,4 & 20,9 & 14,4 & 6,5 & 7,5 & 1,2 & 11,6 & 1,5 & 63,16 \\
\hline $\begin{array}{c}\text { 4. Soil + Restart 2 } \\
\text { times in exchange, } \\
\text { Al + NPK }\end{array}$ & 5,95 & 20,8 & 14,8 & 6,0 & 6,3 & 0,2 & 13,3 & 1,5 & 71,55 \\
\hline $\begin{array}{c}\text { 5. Soil + Restart on } \\
\text { H8.2 + NPK }\end{array}$ & 6,55 & 21,0 & 15,8 & 5,2 & 4,3 & 0,0 & 15,2 & 1,5 & 79,52 \\
\hline
\end{tabular}

In variant 5 , complete neutralization of the exchange aluminum by the strong acid system and increase of the $\mathrm{pH}$ to 6.55 is observed. An increase in the calcium content was reported, which increased from $9.6 \mathrm{meq} / 100 \mathrm{~g}$ in the control to $13.3 \mathrm{meq} / 100 \mathrm{~g}$ in the variant with liming compared to 2 times the volume of aluminum and $15.2 \mathrm{meq} / 100 \mathrm{~g}$ in the variant liming compared to the total hydrogen.

There is a slight decrease in $\mathrm{pH}$ in water in the variant with mineral fertilization. The increase in soil $\mathrm{pH}$ is associated with an increase in the degree of saturation with bases. As the amount of ameliorant increases, so does the degree of base saturation. It increased from 52.38 to 63.16 in the third option and 71.55 and 79.59 in the fourth and fifth options, respectively.

A positive result achieved by the liming is the reduction of the mobility of heavy metals in the soil. Reaction of heavy metals with calciumcontaining ameliorants results in more difficult-todissolve compounds. This reduces their mobility and makes them more difficult for plants to digest. Lime in practice is used for reclamation of soils contaminated with heavy metals [11].

From the soil research at the end of the experiment (Table 9) an increase in $\mathrm{pH}$ was established, as in the variants varied by $1 / 2$ of vol. However, this increase is minimal, and in the variants reclaimed compared to $\mathrm{H}_{8.2}$ it is the largest. As the amount of ameliorant increases, the $\mathrm{K}_{2} \mathrm{O}$ absorbed by the plants increases, and the mineral nitrogen and mobile phosphorus decrease. A significant increase in the electrical conductivity, respectively the water-soluble salts in the soil solution was found with an increase in the lime rate. In option 5 , the soil has become slightly saline.

Table 9. Agrochemical properties of the soil after harvesting the experiment

\begin{tabular}{|l|c|c|c|c|c|c|}
\hline \multirow{2}{*}{ Variants } & $\mathbf{p H}$ & Humus & $\begin{array}{c}\text { Elektropro } \\
\text { conductivity }\end{array}$ & $\begin{array}{c}\mathbf{\Sigma} \mathbf{N}- \\
\mathbf{N H}_{\mathbf{4}}+\mathbf{N O}_{\mathbf{3}}\end{array}$ & $\mathbf{P}_{\mathbf{2}} \mathbf{O}_{\mathbf{5}}$ & $\mathbf{K}_{\mathbf{2}} \mathbf{O}$ \\
\cline { 2 - 7 } & & $\mathbf{\%}$ & $\mathbf{\mathbf { m S } / \mathbf { c m } ^ { \mathbf { 3 } }}$ & $\mathbf{m g} / \mathbf{k g}$ & \multicolumn{2}{|c|}{$\mathbf{~ \mathbf { g } / \mathbf { 1 0 0 g }}$} \\
\hline 1. Soil control & 5,0 & 2,34 & 0,070 & 35,7 & 2,6 & 11,2 \\
\hline 2. Soil + NPK & 5,1 & 2,36 & 0,245 & 54,1 & 15,9 & 30,5 \\
\hline $\begin{array}{l}\text { 3. Soil + Restart on 1/2 of } \\
\text { exchange, Al + NPK }\end{array}$ & 5,3 & 2,48 & 0,287 & 66,2 & 13,8 & 31,7 \\
\hline $\begin{array}{l}\text { 4. Soil + Restart 2 times in } \\
\text { exchange, Al + NPK }\end{array}$ & 5,9 & 2,66 & 0,294 & 45,5 & 13,0 & 36,3 \\
\hline $\begin{array}{l}\text { 5. Soil + Restart on H8.2+ } \\
\text { NPK }\end{array}$ & 6,6 & 2,54 & 0,420 & 31,1 & 13,8 & 49,4 \\
\hline
\end{tabular}




\section{CONCLUSION}

1. The results of the derived vegetation experiment show, that with increasing the rate of ameliorant (Restart), the yield increases compared to the controls. At the highest rate a decrease in yields is observed. A probable cause of the depression in the development and yield of corn is the disturbed balance in the intake and absorption of nutrients by plants with a significant increase in soil $\mathrm{pH}$. The increase of watersoluble salts, etc., also has a negative effect. danger of salinization.

2. The chemical characteristics of the plant production establish that the measured values of the chemical elements are in optimal concentrations and cannot have a harmful effect on their use as animal feed.

3. The studied chemical parameters in soil samples after maize harvest show, that the increase in soil $\mathrm{pH}$ is associated with an increase in the degree of saturation with bases. With the increase of the amount of the ameliorant Restart, the degree of saturation with bases also increases, as in variant 5 (varied according to $\mathrm{H}_{8.2}$ ) the highest result is reached - 79.52. The exchangeable aluminum also decreases, as in variants 4 and 5 it is absent.

In conclusion, the studies conducted to assess the suitability of the industrial material flow Restart, produced by Devnya Cement, give grounds to define it as a possible and suitable ameliorant for improving the unfavorable properties of acid soils. To correct the acidity of soils with similar acidic properties as in the Devnya region, it may be recommended to apply about $1-2 \mathrm{t} /$ daa of the studied ameliorant.

When determining the norm, the degree of acidity of the soil must first be established in order to avoid digestion and contamination. The next reclamation period should be carried out after at least 5 years, with detailed soil tests to determine the degree of soil acidification.

We recommend that the study be continued by conducting field experiments in order to confirm the results of the study and to refine the reclamation rates, according to the assessment of the respective soil type.

\section{BIBLIOGRAPHY}

1. Banov M. et al. 2019. Assessment of the suitability of an industrial material flow produced by Devnya Cement AD for remediation of acid soils, Report, Archive, IPAZR.

2. Banov, M., N. Dinev, P. Ivanov, V. Tsolova. 2009. Testing of waste products as a means of reclamation of acid soils. In: L. Totev et al. Pavlov (Ed.). Scientific reports Int. scientific conference - "Mining science and geotechnics - a European challenge". ISSN 1314-0469. Luxury Print, pp. 113-120.

3. Ganev, St. 1987. Strongly acidic and weakly acidic nature of soil acidity and determination of the norm for liming of acid soils. Forestry Science, 1, 19-26

4. Ganev, St., A. Arsova. 1990. Methods for determination of strongly acidic and weakly acidic cation exchange in soil. Soil Science and Agrochemistry, 3, 22-33.

5. Kozlovsky, EV, AN Nebolsin, Yu. V. Alekseev, PA Churikov. 1983. Liming of soils. Leningrad, Izd. Colossus, 288p.

6. Marinova, S., N. Katijotes, E. Zlatareva. 2018. Evaluation of lime sludge and ash from wood burning as ameliorants on acid soils "5 int. Conference "Ecological Engineering and Environmental Protection - Plovdiv, vol. 1.

7. Nikova, I., 2008. Physico-chemical assessment and reclamation of acid soils. Dissertation for the educational and scientific degree "Doctor"

8. Palaveev, T., T. Totev. 1979. Acidity of soils and agromethods for its removal. Zemizdat, Sofia, $207 \mathrm{p}$.

9. Zlatareva, E., Sv. Marinova. 2016. Evaluation of lime sludge and ash from wood burning as ameliorants on acid soils.

10. Zlatareva, E., Sv. Marinova, N. Catigottes. 2019. Establishing the effect of waste lime materials on the yield and quality of plant production. Participation of "EcoMountain-2019"

11. Dinev N., I. Nikova, R. Sechkova, M. Banov, 2008. Remediation strategies for acid contaminated soils. General and applied plant physiology, vol. XXXIV, 3-4, 397-40

\section{Prof. Svetla Marinova, PhD Assoc.Prof. Elena Zlatareva, PhD}

Institute of Soil Science, agrotechnology and plants protection "N. Poushkarov", 7, Shose Bankya Str., Sofia, Bulgaria e-mail:svetla_mar@mail.bg 